\title{
BMJ Open Importance of reporting survival as incidence: a cross-sectional comparative study on out-of-hospital cardiac arrest registry data from Germany and Norway
}

\author{
Ingvild Beathe Myrhaugen Tjelmeland (D) , 1,2,3 Kristin Alm-Kruse, ${ }^{3,4}$ \\ Jan-Thorsten Grasner, ${ }^{1,5}$ Cecilie Benedicte Isern, ${ }^{2,3}$ Barbara Jakisch, ${ }^{6}$ \\ Jo Kramer-Johansen, ${ }^{2,3}$ Niels Renzing, ${ }^{1}$ Jan Wnent, ${ }^{1,7}$ Stephan Seewald ${ }^{1,5}$
}

To cite: Tjelmeland IBM, Alm-Kruse K, Grasner J-T, et al. Importance of reporting survival as incidence: a crosssectional comparative study on out-of-hospital cardiac arrest registry data from Germany and Norway. BMJ Open 2022;12:e058381. doi:10.1136/ bmjopen-2021-058381

- Prepublication history for this paper is available online. To view these files, please visit the journal online (http://dx.doi. org/10.1136/bmjopen-2021058381).

Received 15 October 2021 Accepted 01 February 2022
Check for updates

(C) Author(s) (or their employer(s)) 2022. Re-use permitted under CC BY-NC. No commercial re-use. See rights and permissions. Published by BMJ.

For numbered affiliations see end of article.

Correspondence to

Mrs Ingvild Beathe Myrhaugen Tjelmeland; ingvild@nakos.no

\section{ABSTRACT}

Objectives Health registries are a unique source of information about current practice and can describe disease burden in a population. We aimed to understand similarities and differences in the German Resuscitation Registry (GRR) and the Norwegian Cardiac Arrest Registry (NorCAR) and compare incidence and survival for patients resuscitated after out-of-hospital cardiac arrest.

Design A cross-sectional comparative analysis reporting incidence and outcome on a population level.

Setting We included data from the cardiac arrest registries in Germany and Norway.

Participants Patients resuscitated between 1 January 2015 and 31 December 2019 were included, resulting in 29222 cases from GRR and 16406 cases from NorCAR. From GRR, only emergency medical services (EMS) reporting survival information for patients admitted to the hospital were included.

Primary and secondary outcome measures This study focused on the EMS systems, the registries and the patients included in both registries. The results compare the total incidence, incidence of patients resuscitated by EMS, and the incidence of survival.

Results We found an incidence of 68 per 100000 inhabitants in GRR and 63 in NorCAR. The incidence of patients treated by EMS was 67 in GRR and 53 in NorCAR. The incidence of patients arriving at a hospital was higher in GRR (24.3) than in NorCAR (15.1), but survival was similar (8 in GRR and 7.8 in NorCAR).

Conclusion GRR is a voluntary registry, and in-hospital information is not reported for all cases. NorCAR has mandatory reporting from all EMS and hospitals. EMS in Germany starts treatment on more patients and bring a higher number to hospital, but we found no difference in the incidence of survival. This study has improved our knowledge of both registries and highlighted the importance of reporting survival as incidence when comparing registries.

\section{INTRODUCTION}

Health registries are a unique source of information about current practice and the first of many steps in improving treatment and care. ${ }^{1}$ Registries can be used for epidemiological
Strengths and limitations of this study

- Prospective cardiac arrest registries provide knowledge about treatment and results in real life in contrast to highly selected populations in clinical studies.

- We used data from a mandatory registry covering an entire country and a voluntary registry covering parts of a country.

- We use incidence per 100000 inhabitants when presenting the rate of cases and the rate of survival in the out-of-hospital cardiac arrest population.

- In Germany, the General Data Protection Regulation interpretation is associated with more missing information on survival status than results from the Norwegian registry.

and outcome reports for many health conditions, describe the burden of disease and the effectiveness of treatment. Registries can also be beneficial in quality improvement projects, ${ }^{2}$ and for political accountability. Registries on out-of-hospital cardiac arrest (OHCA) are of particular interest as a successful outcome depends on a complex chain involving the population, medical dispatch, emergency medical services (EMS) and hospital treatment. ${ }^{3}$

For a society to improve survival after OHCA, detailed and reliable data must guide our efforts. Several studies and reviews have compared outcomes across countries and jurisdictions. $^{4-8}$ Despite the international consensus of which data to collect and how to collect it, ${ }^{9}$ results vary greatly, even within groups presumed to have similar characteristics. ${ }^{10} 11$ Survival is often reported as rates and not as incidence per 100000 inhabitants, making comparisons almost impossible due to the varying denominator. Two big studies reporting on cardiac arrest in Europe both 
reported return of spontaneous circulation (ROSC) and survival as percentages and not as incidence. ${ }^{68}$ The same use of percentages can be seen in the yearly reports from the Cardiac Arrest Registry to Enhance Survival in the $\mathrm{USA}^{12}$ and the first report from the International Liaison Committee on Resuscitation. ${ }^{7}$

This study aimed to understand the German Resuscitation Registry (GRR) and the Norwegian Cardiac Arrest Registry (NorCAR), to compare the EMS systems in Germany and Norway, and to report on the treatment given to patients suffering OHCA. We also aimed to compare a mandatory and a voluntary registry, the incidence of included patients, and incidence of survival. As a background for our analysis, we describe the care provided to OHCA patients and data collection into the registries. We present incidence and outcome in the catchment areas and the Utstein comparator group (witnessed by a bystander and having a shockable rhythm). ${ }^{9}$

\section{METHODS}

\section{Healthcare in Germany}

Germany is a federal parliamentary republic consisting of 16 states and covers $357386 \mathrm{~km}^{2}$. In 2019 Germany had 85 million inhabitants. The population density was about 238 inhabitants per $\mathrm{km}^{2}{ }^{213}$

The EMS in Germany is a two-tiered system consisting of emergency medical technicians (EMT) or paramedics and emergency-physician. Teaching paramedics often have education on a bachelor level, but this is not common for paramedics working in the field. Ambulances personnel provide primary care and patient transportation, and a medical vehicle or helicopter carries an emergency physician to the patient location for all cardiac arrest situations. ${ }^{14}$

A standard emergency number, 1-1-2, terminates at an Emergency Medical Communications Centres (EMCC). EMTs or paramedics are call-takers. Each state organises their specialist healthcare, resulting in differences in the EMCCs. There are 1900 hospitals with a 24/7 emergency department, resulting in 23 hospitals per 1 million inhabitants. Due to German data protection laws, using a single patient identification number in healthcare is not possible. Health insurance or the state covers healthcare in Germany. ${ }^{13}$

Hospitals with an internal medicine department and an emergency department treat patients that survive to hospital admission. Recently a unique certification for cardiac-arrest centres was established. To get certified, hospitals must fulfil criteria, including $24 / 7$ percutaneous coronary intervention (PCI) service and have protocols for postcardiac arrest care.

\section{Healthcare in Norway}

Norway is a representative democratic constitutional monarchy covering a total land area of $304282 \mathrm{~km}^{2}$ and had 5.3million inhabitants in 2019. The population density is about 18 inhabitants per km. ${ }^{213}$
The EMS in Norway consists of ambulances, boats and helicopters, search and rescue helicopters, small aeroplanes and physician-manned cars. The helicopters, planes and physician-manned cars have rescue-EMS personnel and an anesthesiologist/emergency physician. Ambulance personnel have an education level of minimum upper secondary school and a 2-year apprenticeship. In recent years, several universities have established bachelor programmes for paramedics.

The Norwegian single-payer public insurance covers all aspects of healthcare, including the ambulance service. For medical emergencies, there is a dedicated telephone number, 1-1-3, that terminates at 16 local EMCC. Nurses and ambulance personnel receive the calls. Specialist healthcare is organised in four regional and 19 local health trusts, with 50 hospitals with an emergency department, resulting in 9.4 hospitals per 1 million inhabitants. ${ }^{13}$ Based on national recommendations, all hospitals have protocols for care for patients surviving to hospital admission. Within each region in Norway, referral hospitals offer 24/7 PCI, and bypass protocols are in place. A personal identification number identifies the patient in all contact with specialist healthcare.

\section{German Resuscitation Registry}

GRR is a voluntary based registry established in 2007 by the German Society of Anaesthesiology and Intensive Care Medicine. In 2019, GRR received information from EMS covering 26.6 million inhabitants (31\% of the inhabitants of Germany and with EMS from all parts of the country). The registry includes fully anonymised data from patients suffering cardiac arrest both outside and in the hospital. In addition to data collection and benchmarking, GRR provides risk adjustment analysis for its participants. ${ }^{15} 16$

The inclusion criteria in GRR is; all EMS attended cardiac arrests. Participants in the registry enter information from the EMS and may add in-hospital treatment, survival to hospital discharge and 30-day survival if this information is available. Due to different interpretations of the General Data Protection Regulation, in-hospital treatment of OHCA patients is not always available for the reporting EMS system. An area with good data quality has; an incidence above 30/100 000 inhabitants per year, ROSC in less than $80 \%$ of cases, information about ROSC-after-cardiac-arrest in more than $60 \%$ of the cases, and, if relevant, documented hospital care available for more than $30 \%$ of the cases. ${ }^{17}$

\section{Norwegian Cardiac Arrest Registry}

National Advisory Unit on Prehospital Emergency Medicine established NorCAR in 2002, and the registry received status as a mandatory national health registry in September 2013. The registry includes cardiac arrests both outside and in the hospital. By May 2016, all health trusts reported OHCA to the registry. Oslo University Hospital hosts the registry, and the Norwegian Institute of Public Health has the legal responsibility. ${ }^{18}$ 
Inclusion criteria in the registry is; patients suffering cardiac arrest, where bystanders, first responders or healthcare professionals start any kind of treatment. Treatment is basic or advanced cardiopulmonary resuscitation (CPR) or defibrillation. Patients suffering cardiac arrest that do not receive any CPR are not included in the registry. ${ }^{18}$

\section{Participants}

This study included all patients from NorCAR and all patients where resuscitation was attempted from areas in GRR with good data quality. The patients had a cardiac arrest between 1 January 2015 and 31 December 2019.

\section{Variables}

All data variables in the registries are available in the local languages. Variables were translated into English to make comparison possible and to ensure an equal understanding of the definitions. Although both registries use the Utstein definitions, the German registry reports any ROSC while the Norwegian registry reports sustained ROSC (ROSC for more than 20 min or to hospital admission). Therefore, the shared data points 'Transport to hospital' and 'Arrival to hospital with ROSC' was used. For the overall survival, we used survival to hospital discharge in GRR and 30-day survival in NorCAR.

\section{Patient and public involvement}

NorCARs steering committee has a user representative who has been actively involved in planning this and earlier projects in NorCAR. He represents the patient organisation National Association of Heart and Lung Disease with 54000 members. Through his network of fellow user representatives, he provides a channel for communication to the patient population and the boards of the health trusts. At several meetings, the user representative has expressed concern regarding the difficulties of comparing data from different regions in Norway and differences between countries. We believe this study addresses these challenges, and we also suggest a method for reducing the reported differences by presenting results as incidence, not at percentages.

\section{Checklist}

The Strengthening the Reporting of Observational Studies in Epidemiology cross-sectional reporting guideline was used when formatting the manuscript. ${ }^{19}$

\section{Statistical methods}

We provide descriptive measures as mean with $\mathrm{SD}$ or median, as appropriate according to the data distribution. We calculated incidence for regions reporting part of a year by dividing the number of patients by the corresponding fraction of the person-years for that region. For bystander efforts (CPR and use of public defibrillators) and calculation of EMS response intervals, we excluded EMS witnessed cardiac arrests. We analysed the Utstein comparator group based on the 2014 definition, ${ }^{9}$ including patients with a bystander-witnessed collapse

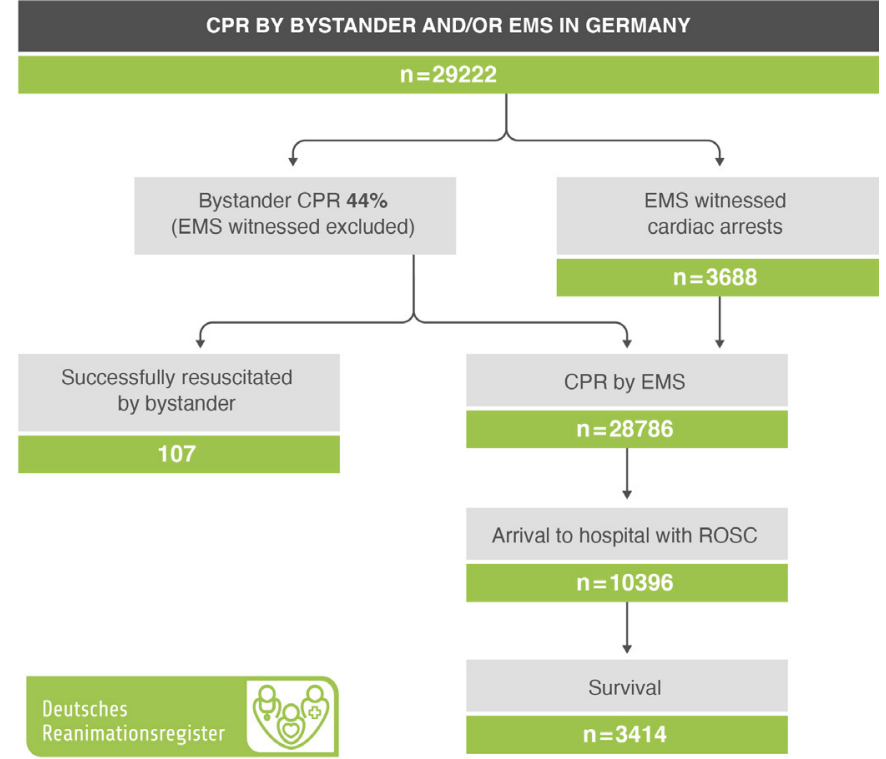

Figure 1 Flow of patients in the German Resuscitation Registry. CPR, cardiopulmonary resuscitation; EMS, emergency medical services; ROSC, return of spontaneous circulation.

and an initial shockable rhythm. For the cause of arrest, we used the Utstein definition from 2004. ${ }^{20}$ During several personal meetings, we reviewed the results and rechecked the analyses. Figures 1 and 2 describe the inclusion and exclusion of patients in GRR and NorCAR. Analyses were carried out using IBM SPSS Statistics V.27. $P$ values are calculated based on the incidence, and a $p$ value $<0.05$ was considered statistically significant.

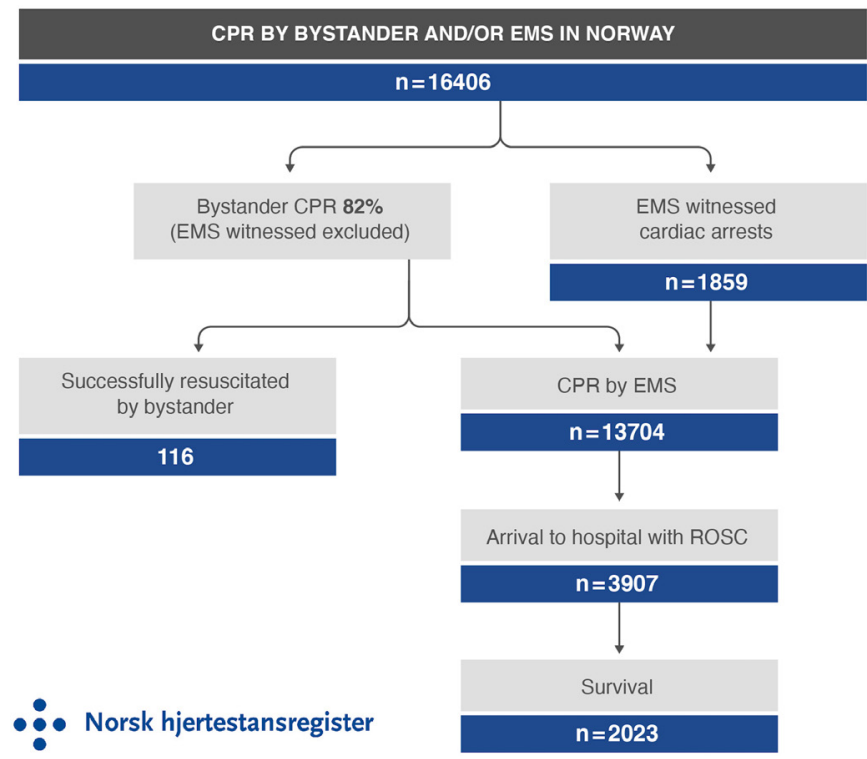

Figure 2 Flow of patients in the Norwegian Cardiac Arrest Registry. CPR, cardiopulmonary resuscitation; EMS, emergency medical services; ROSC, return of spontaneous circulation. 
Table 1 Cardiac arrest characteristics for all resuscitated patients in GRR and NorCAR, 2015-2019

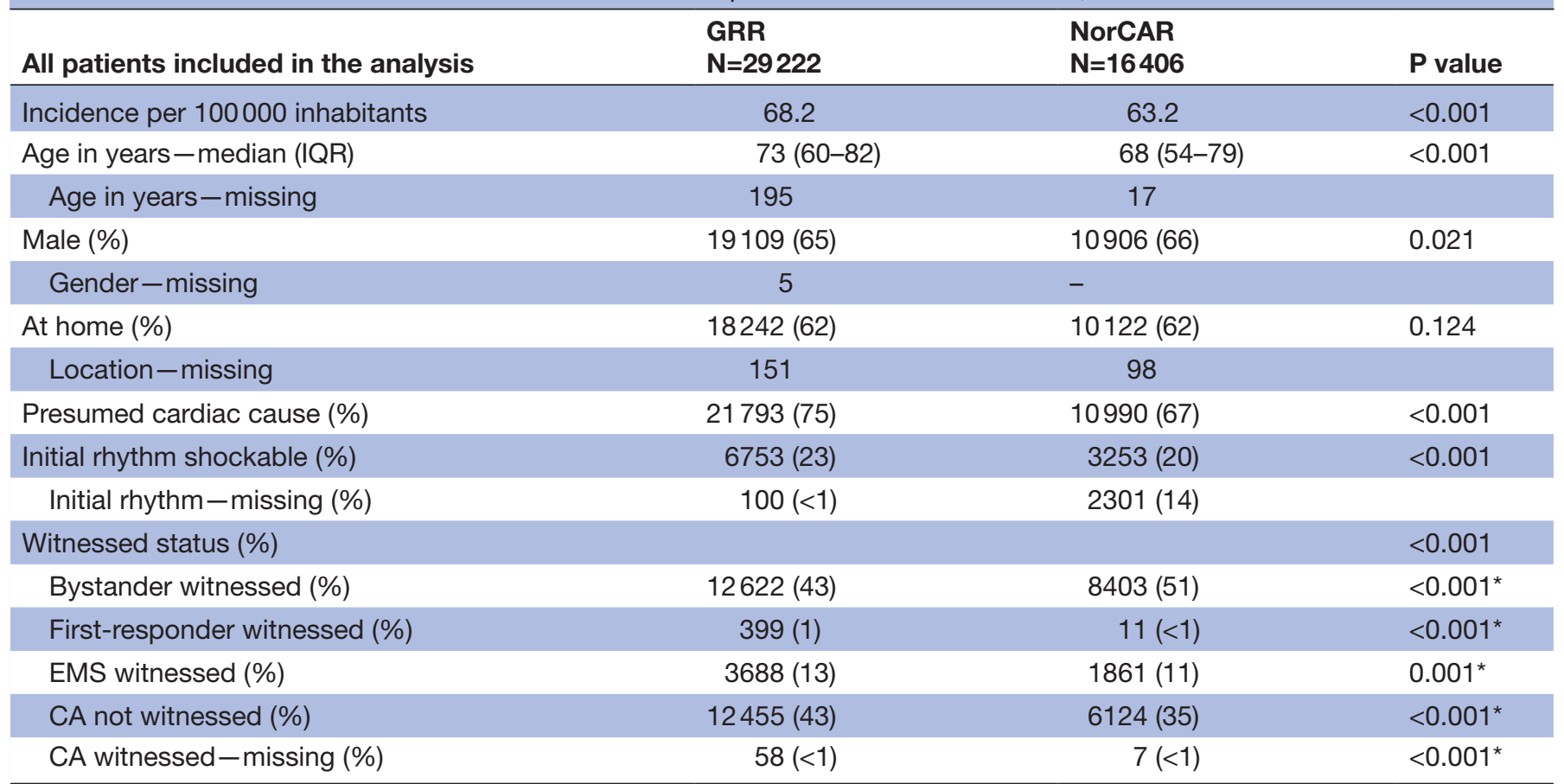

${ }^{*} \mathrm{P}$ values from post hoc testing ( $\chi^{2}$ test) and corrected by the Bonferroni method.

CA, cardiac arrest; CPR, cardiopulmonary resuscitation; EMS, emergency medical service; GRR, German Resuscitation Registry-areas with good data quality; NorCAR, Norwegian Cardiac Arrest Registry.

\section{RESULTS}

\section{Demographics}

Between 2015 and 2019, 29222 cases were registered in GRR (68 per 100000 inhabitants) and 16406 cases in NorCAR (63 per 100000 inhabitants). The patients in GRR were older than the patients in NorCAR, more often had presumed cardiac cause, had a shockable rhythm and were more likely to be unwitnessed (table 1). Gender and the location of arrest were similar.

\section{All patients except EMS witnessed cardiac arrests}

The incidence of patients receiving bystander CPR, having a public defibrillator connected, and receiving a shock before EMS arrival was higher in NorCAR than in GRR, giving a higher number of patients successfully resuscitated before EMS arrival (table 2 ).

The median response interval was $8 \mathrm{~min}$ in GRR (IQR 6-10) and $9 \mathrm{~min}$ in NorCAR (IQR 6-14). In NorCAR, the EMS personnel chooses not to start resuscitation, despite bystanders having started CPR, in $16 \%$ of the patients, most of whom had a pulse on EMS arrival. The proportion of patients not treated by EMS in GRR was $1 \%$.

\section{CPR by EMS}

The reported incidence of patients resuscitated by EMS per 100000 inhabitants was 67 in GRR and 53 in NorCAR. More patients were declared dead on scene in NorCAR, while the incidence of patients 'Transported to hospital'

Table 2 Patients resuscitated by bystander or EMS, except EMS and first responder witnessed cardiac arrests

\begin{tabular}{|c|c|c|c|}
\hline All patients except EMS and first responder witnessed & $\begin{array}{l}\text { GRR } \\
\mathrm{N}=25135\end{array}$ & $\begin{array}{l}\text { NorCAR } \\
\mathrm{N}=14545\end{array}$ & P value \\
\hline Incidence per 100000 inhabitants & 58.7 & 55.2 & $<0.001$ \\
\hline Response interval-missing (\%) & $608(2)$ & $252(2)$ & \\
\hline Bystander CPR (\%) & $11056(44)$ & $11803(82)$ & $<0.001$ \\
\hline Shocked by public defibrillator before EMS arrival, and ROSC on EMS arrival (\%) & $107(0.4)$ & $116(0.8)$ & $<0.001$ \\
\hline
\end{tabular}

*Percentage calculated based on the number of connected public defibrillators.

CPR, cardiopulmonary resuscitation; EMS, emergency medical service; GRR, German Resuscitation Registry-areas with good quality data; NorCAR, Norwegian Cardiac Arrest Registry; ROSC, return of spontaneous circulation. 
Table 3 Outcome for all EMS-treated patients per 100000 inhabitants

\begin{tabular}{|c|c|c|c|}
\hline CPR by EMS & $\begin{array}{l}\text { GRR } \\
\mathrm{N}=28786\end{array}$ & $\begin{array}{l}\text { NorCAR } \\
\mathrm{N}=13704\end{array}$ & $P$ value \\
\hline Incidence of EMS treated patients & 67.2 & 52.8 & $<0.001$ \\
\hline \multicolumn{4}{|l|}{ Status on arrival to hospital } \\
\hline Incidence of arrival with ROSC (\%) & $24.3(36)$ & $15.1(29)$ & $<0.001$ \\
\hline Incidence of survival (\%)‡ & $8.0(12)$ & $7.8(15)$ & 0.42 \\
\hline
\end{tabular}

${ }^{*}$ Declared dead/transport to hospital-missing 265 (1\%) in GRR and 104 (1\%) in NorCAR.

†24-hour survival-missing $2273(8 \%)$ in GRR and $195(1 \%)$ in NorCAR.

¥Survival-missing 1931 (7\%) in GRR and 165 (1\%) in NorCAR.

CPR, cardiopulmonary resuscitation; EMS, emergency medical service; GRR, German Resuscitation Registry-areas with good data quality;

NorCAR, Norwegian Cardiac Arrest Registry; PCl, percutaneous coronary intervention; ROSC, return of spontaneous circulation.

and 'Arrival to hospital with ROSC' was higher in GRR (table 3). The incidence of 24-hour survival was higher in GRR, but there was no statistical difference in overall survival (figure 3).

The use of a mechanical chest compressions device was higher in NorCAR than in GRR (4020 of $13704(29 \%)$ vs 3223 of $28786(11 \%)$, respectively, $\mathrm{p}<0.001)$. For patients transported to the hospital and arriving with ROSC or ongoing CPR, 1987 of 13571 (15\%) of the patients in GRR and 1079 of 4962 (22\%) of the patients in NorCAR were transported directly to the PCI lab on arrival.

\section{Utstein comparator group}

The incidence of patients in the Utstein group was higher in GRR, but they constituted a smaller proportion of the EMS-treated population (14\% vs 17\%). Bystander CPR was higher in NorCAR (1961 of $2274(86 \%)$ ) than in GRR

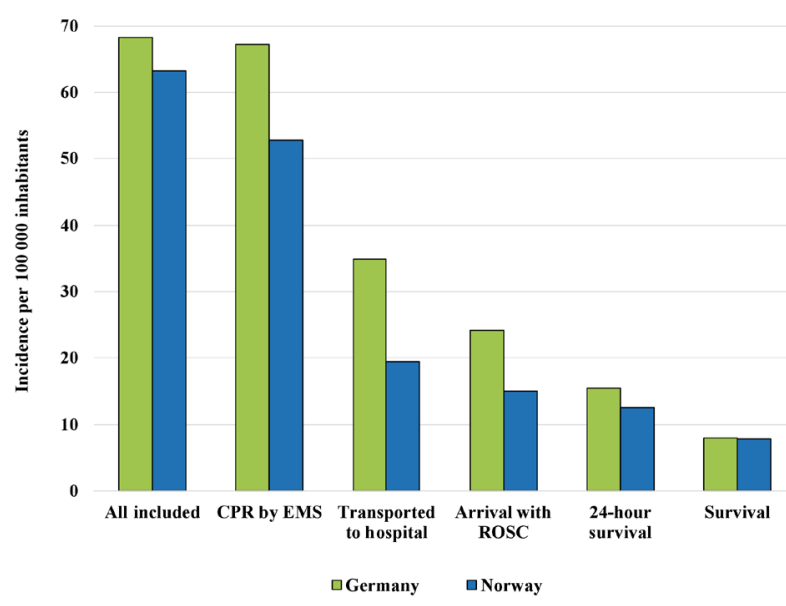

Figure 3 All resuscitated patients included in the German and the Norwegian Cardiac Arrest Registries per 100000 inhabitants from 2015 and 2019. CPR, cardiopulmonary resuscitation; EMS, emergency medical personnel, ROSC, return of spontaneous circulation.
(2726 of $4155(66 \%))$. For patients transported to the hospital and arriving with ROSC or ongoing CPR, 879 of $3362(26 \%)$ of the patients in GRR and 548 of 1502 (37\%) of the patients in NorCAR were transported directly to the PCI lab on arrival. The incidence of prehospital ROSC and survival to 24 hours was higher in GRR (table 4 and figure 4), but the incidence of overall survival was higher in NorCAR.

\section{DISCUSSION}

The incidence of cardiac arrest per 100000 inhabitants is higher in GRR compared with NorCAR. GRR reports a higher incidence of EMS treated patients, a higher incidence of patients transported to the hospital and a higher incidence of patients arriving in the hospital with ROSC. The overall incidence of survival is similar in both countries. For the Utstein comparator group, the incidence of survival is marginally higher in NorCAR. Patient characteristics in both countries, such as age and gender, confirms previous reports. ${ }^{6}$

Using registry data from two different countries, we encountered some challenges. A certain amount of recoding of variables had to be done, notably using survival to hospital discharge in GRR and 30-day survival in NorCAR. Both survival to discharge, and 30-day survival, have been used interchangeably in other international studies, including the latest recommendations for reporting. ${ }^{9}$ Also, in a registry, it is not easy to verify the completeness of cases. ${ }^{21}$ Most EMS in Europe have a paper-based reporting system, and there are no electronically available patient charts to use as controls. Both GRR and NorCAR are dependent on the attending EMS personnel remembering to submit a form after the event. This form is then manually entered into the registry database by data managers.

Comparing a voluntary registry with a mandatory registry, we were worried about missing information. In the latest published update on uniform reporting of 
Table 4 Outcome for the Utstein comparator group per 100000 inhabitants

\begin{tabular}{|c|c|c|c|}
\hline Utstein comparator group & $\begin{array}{l}\text { GRR } \\
\mathrm{N}=4155\end{array}$ & $\begin{array}{l}\text { NorCAR } \\
\mathrm{N}=2274\end{array}$ & $P$ value \\
\hline Incidence in the Utstein comparator group & 9.7 & 8.8 & $<0.001$ \\
\hline \multicolumn{4}{|l|}{ Status on arrival to hospital } \\
\hline Incidence of arrival to hospital with ROSC (\%) & $6.4(66)$ & $5.0(57)$ & $<0.001$ \\
\hline Incidence of survival (\%)‡ & $3.5(36)$ & $3.8(43)$ & 0.04 \\
\hline
\end{tabular}

Utstein comparator group - out-of-hospital cardiac arrest (OHCA) witnessed by a bystander and shockable first rhythm.

*Declared dead/transport to hospital-missing, $16(<1 \%)$ in GRR and $1(<1 \%)$ in NorCAR.

†24-hour survival-missing, 541 (13\%) in GRR and 28 (1\%) in NorCAR.

‡Survival-missing, 455 (11\%) in GRR and 24 (1\%) in NorCAR.

CPR, cardiopulmonary resuscitation; EMS, emergency medical service; GRR, German Resuscitation Registry-areas with good quality data;

NorCAR, Norwegian Cardiac Arrest Registry; ROSC, return of spontaneous circulation.

cardiac arrest, the Utstein reporting format, the authors stress the importance of reducing missing information. ${ }^{9}$ We found that the rate of missing information is overall higher in GRR, and the variable with the highest missing rate is survival (7\%). Survival information is mostly missing from entire hospitals, indicating that missing cases include both survivors and non-survivors. Due to GRR being a voluntary registry, information on cardiac arrest cases is not available from the entire country. Results are, however, comparable to overall results in yearly reports from GRR and the data in this study are considered to be representable for all regions reporting to the registry. ${ }^{17}$

Reporting the incidence of cardiac arrest is primarily done using the number of patients per 100000 inhabitants in the population served by the EMS. ${ }^{6-8}$ Survival, however, is often presented as a proportion of the EMS treated patients. Percentages are presumed to be easier

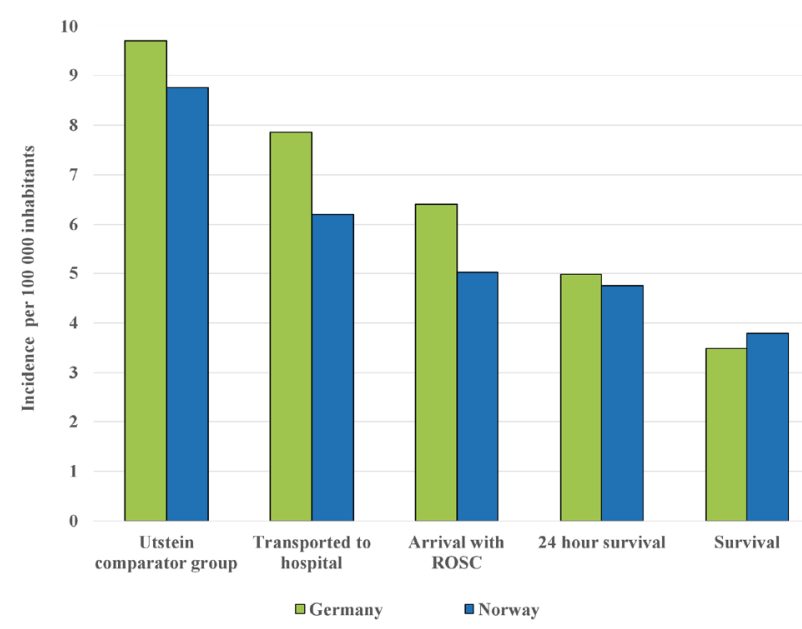

Figure 4 The Utstein comparator group. Incidence per 100000 . Utstein comparator group is cardiac arrest witnessed by a bystander and having a shockable rhythm. ROSC, return of spontaneous circulation. to understand and make comparability with already published data more straightforward. During the COVID-19 pandemic, healthcare professionals and the general public have become more used to population incidence as a measurement, and we believe it is time for survival after cardiac arrest to be published in this way. In 1993, Becker $e t a t^{22}$ published an analysis on the relationship between reported incidence and survival rates and advised incidence and not percentages. When there is more than a threefold difference in the incidence of EMS treated patients, as reported in the latest EuReCa study, ${ }^{6}$ higher survival rates do not necessarily represent better quality of care. The difference could be that a registry with a low survival percentage is better at identifying all patients resuscitated by the EMS. Our study shows that the incidence of survival is similar in GRR and NorCAR, but the incidence of included patients is not. If we calculate the survival rate based on the number of patients resuscitated by the EMS, Norway seems to have better survival $(15 \%)$ than Germany (12\%).

Differences in the incidence of cardiac arrest overall, and the EMS treated patients in particular, could be due to differences in public health in general and cardiovascular health in particular. According to the European Unions' statistics, cardiovascular disease deaths account for $37 \%$ of deaths in Germany, but only $26 \%$ in Norway. ${ }^{23}$ Population density, geography and placement of ambulances might also have an impact. Both countries adhere to European guidelines for resuscitation, ${ }^{24}$ but in Norway, withholding care in the prehospital setting is more common.

Response interval is the time interval from a call is received at an EMCC to the first ambulance arrives at the defined address. Response interval should ideally include the delay until EMS personnel are at the patient side, but the latter time point remains elusive due to manual registration. The extended response interval in Norway provides dispatchers more time to help bystanders start 
CPR, connect and use a defibrillator, and is associated with a significantly higher number of patients having been successfully resuscitated before EMS arrival. On the downside, it probably also has a negative effect on survival. ${ }^{25} 26$ The narrow distribution of response intervals in GRR (25-percentiles and 75-percentiles of 6 and $10 \mathrm{~min})$ compared with the broader distribution found in NorCAR (25-percentiles and 75-percentiles of 6 and $14 \mathrm{~min}$ ) indicates differences caused by geography and population density. Extended response intervals might also explain the lower incidence of EMS treated patients in Norway as bystanders or EMS personnel perceive resuscitation as futile when the response interval is prolonged.

The Utstein comparator group is a subgroup that enables comparison between countries. ${ }^{9}$ This subgroup has a more uniform treatment recommendation than the total population of patients with OHCA and does not include cases with unknown delays from collapse. Our results confirm that the differences between our countries also extends to this specific group. Differences between countries in the Utstein comparator group have been shown in several studies previously. ${ }^{6} 1027$

In Norway, all hospitals are state-owned, and the Norwegian Directory of Health issues guidelines for treatment. Results from quality registries are published yearly, naming and shaming hospitals and their adherence to guidelines. ${ }^{28}$ There is a bypass protocol for the nearest University Hospital capable of performing PCI for cardiac arrest patients. If transport duration is prolonged, there are guidelines for prehospital treatment, including thrombolysis. In Norway, the in-hospital treatment after OHCA is standardised, but this is not the case in most German hospitals. In 2019, the German Resuscitation Council started an initiative to certify cardiac arrest centres, and GRR extended the benchmarking facilities for cardiac arrest centres. ${ }^{29}$

Several factors are associated with increased survival after OHCA; younger age, presumed cardiac cause, shockable first rhythm, witnessed collapse, location of arrest in a public place, bystander CPR, early shock by a defibrillator, a short time from collapse to arrival of EMS and good postresuscitation care including temperature control and PCI. ${ }^{15}{ }^{30}$ Compared with GRR, the patients in NorCAR are younger, witnessed collapse is more common and more than four out of five receive bystander CPR. Compared with NorCAR, the patients in GRR more often have presumed cardiac cause, initial rhythm is shockable, and the EMS's response interval is shorter. There is a mix of factors associated with survival in both countries.

This study has helped us identify differences and similarities in the cardiac arrest registries in Germany and Norway and identify potential confounders for future studies. In this comparison, we cannot tease out the relative importance of factors associated with increased survival, and in future studies, we should analyse individual cases using more sophisticated statistical methods.
Implication for the future

Based on our findings, we recommend all nations make cardiac arrest a reportable condition. Making reporting mandatory provides an opportunity to follow a patient through the healthcare system and evaluate how an intervention affects care, health and cost. ${ }^{31}$ When participation in a registry is voluntary, it is difficult to conclude that results are representative of a larger population. If cardiac arrest is not a reportable condition, there is a greater risk that EMS systems and hospitals deliberately do not participate because of fear that their level of care is suboptimal.

Treating and reporting many patients that do not survive will give a low survival rate while treating and reporting a low number of non-survivors will give a high survival rate. Reporting inclusion and results as incidence per 100000 inhabitants is essential if we wish to know the burden of disease in a population, and it is a way of making results more comparable as variation in how prehospital providers perceive futility and variable reporting practices will have less impact on the overall reported survival. ${ }^{6-812}$

\section{CONCLUSION}

This cross-sectional study shows the importance of comparing the incidence of survival based on the population served and not on the percentage of EMS treated patients. When comparing data from OHCA registries, especially when comparing survival, we recommend using incidence per 100000 inhabitants, and we believe it is time to stop reporting survival as percentages.

We found that the EMS in Germany started CPR on a higher number of cardiac arrest patients, and the incidence of patients transported to the hospital and arriving with ROSC is higher than in NorCAR. We speculate that the difference in overall incidence and incidence of EMS treated patients is due to an interaction between response intervals, bystander CPR, age and EMS organisation. A multivariate analysis should be performed to better understand our findings.

\section{Author affiliations}

${ }^{1}$ Institute for Emergency Medicine, Universitätsklinikum Schleswig-Holstein, Kiel, Germany

${ }^{2}$ Division of Prehospital Services, Oslo University Hospital, Oslo, Norway ${ }^{3}$ Faculty of Medicine, Institute of Clinical Medicine, University of Oslo, Oslo, Norway ${ }^{4}$ Division of Emergencies and Critical Care, Oslo University Hospital, Oslo, Norway ${ }^{5}$ Department of Anaesthesiology and Intensive Care Medicine, Universitätsklinikum Schleswig-Holstein, Kiel, Germany

${ }^{6}$ Organization \& Corporate Development, imland gGmbH, Rendsburg, SchleswigHolstein, Germany

${ }^{7}$ University of Namibia School of Medicine, Windhoek, Namibia

Contributors IBMT: guarantor, contributed to the conception, planning, design, acquisition of data, analysis and interpretation of data, the first draft of the article, revision of draft and approval of the final manuscript. KA-K: contributed to the conception, planning, design, interpretation of data, the first draft of the article, revision of draft and approval of the final manuscript. J-TG: contributed to the conception, planning, design, acquisition of data, analysis and interpretation of data, the first draft of the article, revision of draft and approval of the final 
manuscript. CBI: contributed to the conception, planning, design, revision of draft and approval of the final manuscript. BJ: contributed to the conception, planning, design, acquisition of data, analysis and interpretation of data, revision of draft and approval of the final manuscript. JK-J: contributed to the conception, planning, design, analysis and interpretation of data, the first draft of the article, revision of draft and approval of the final manuscript. NR: contributed to the conception, planning, design, revision of draft and approval of the final manuscript. JW: contributed to the conception, planning, design, acquisition of data, analysis and interpretation of data, the first draft of the article, revision of draft and approval of the final manuscript. SS: contributed to the conception, planning, design, acquisition of data, analysis and interpretation of data, the first draft of the article, revision of draft and approval of the final manuscript.

Funding This work was supported by the German-Norwegian student centre at Christian-Albrechts-University in Kiel; the funds facilitate meetings in Kiel and 0slo. Award/grant number: not applicable.

Competing interests J-TG reports grants from the German Anaesthesiology Association during the conduct of the study; personal speaker fee and travel cost outside the submitted work. All authors report receiving a grant from the German-Norwegian student centre at Christian-Albrechts-University in Kiel. Nonfinancial associations: JW and SS are members of the steering committee of the German Resuscitation Registry. JK-J is a member of the Steering Committee of the Norwegian Cardiac Arrest Registry. IBMT is the leader of the Norwegian Cardiac Arrest Registry.

Patient and public involvement Patients and/or the public were involved in the design, or conduct, or reporting, or dissemination plans of this research. Refer to the Methods section for further details.

\section{Patient consent for publication Not applicable.}

Ethics approval The scientific advisory board of the German Resuscitation Registry (Ref. no.: 20190128_BJ) and the steering committee of the Norwegian Cardiac Arrest Registry has approved the study (reference: 23092019_Article). The study is approved by the ethics committee of the University of Kiel (Ref. no.: D435/21). Informed consent from patients is not needed.

Provenance and peer review Not commissioned; externally peer reviewed.

Data availability statement Data are available upon reasonable request. The data that support the findings of this study are available from the German Resuscitation Registry and the Norwegian Cardiac Arrest Registry through an application to the registry based on the regulation of each registry. Restrictions apply.

Open access This is an open access article distributed in accordance with the Creative Commons Attribution Non Commercial (CC BY-NC 4.0) license, which permits others to distribute, remix, adapt, build upon this work non-commercially, and license their derivative works on different terms, provided the original work is properly cited, appropriate credit is given, any changes made indicated, and the use is non-commercial. See: http://creativecommons.org/licenses/by-nc/4.0/.

\section{ORCID iD}

Ingvild Beathe Myrhaugen Tjelmeland http://orcid.org/0000-0003-0362-1008

\section{REFERENCES}

1 Resuscitation Academy. 10 steps for improving survival from cardiac arrest. resuscitation Academy, 2019. Available: https://globalresusc itationalliance.org/downloads/ebook/10_steps_2019.pdf

2 Chamberlain D. A prize worth the effort: a common European registry of out-of-hospital cardiac arrest. Resuscitation 2011;82:965-6.

3 Cummins RO, Ornato JP, Thies WH, et al. Improving survival from sudden cardiac arrest: the "chain of survival" concept. A statement for health professionals from the Advanced Cardiac Life Support Subcommittee and the Emergency Cardiac Care Committee, American Heart Association. Circulation 1991;83:1832-47.

4 Nichol G, Thomas E, Callaway CW, et al. Regional variation in out-of-hospital cardiac arrest incidence and outcome. JAMA 2008;300:1423-31.

5 Berdowski J, Berg RA, Tijssen JGP, et al. Global incidences of outof-hospital cardiac arrest and survival rates: systematic review of 67 prospective studies. Resuscitation 2010;81:1479-87.

6 Gräsner J-T, Wnent J, Herlitz J, et al. Survival after out-of-hospital cardiac arrest in Europe - Results of the EuReCa TWO study. Resuscitation 2020;148:218-26.

7 Kiguchi T, Okubo M, Nishiyama C, et al. Out-Of-Hospital cardiac arrest across the world: first report from the International liaison Committee on resuscitation (ILCOR). Resuscitation 2020;152:39-49.
8 Gräsner J-T, Lefering R, Koster RW, et al. EuReCa ONE-27 nations, one Europe, one registry: a prospective one month analysis of out-of-hospital cardiac arrest outcomes in 27 countries in Europe. Resuscitation 2016;105:188-95.

9 Perkins GD, Jacobs IG, Nadkarni VM, et al. Cardiac arrest and cardiopulmonary resuscitation outcome reports: update of the Utstein resuscitation registry templates for out-of-hospital cardiac arrest: a statement for healthcare professionals from a task force of the International liaison Committee on resuscitation (American heart association, European resuscitation Council, Australian and New Zealand Council on resuscitation, heart and stroke Foundation of Canada, InterAmerican heart Foundation, resuscitation Council of southern Africa, resuscitation Council of Asia); and the American heart association emergency cardiovascular care Committee and the Council on cardiopulmonary, critical care, perioperative and resuscitation. Resuscitation 2015;96:328-40.

10 Masterson S, Strömsöe A, Cullinan J, et al. Apples to apples: can differences in out-of-hospital cardiac arrest incidence and outcomes between Sweden and ireland be explained by core Utstein variables? Scand J Trauma Resusc Emerg Med 2018;26:37.

11 Maurer $\mathrm{H}$, Masterson S, Tjelmeland IB, et al. When is a bystander not a bystander any more? a European survey. Resuscitation 2019;136:78-84.

12 McNally B. 2019 annual report cares cardiac arrest registry to enhance survival. . CARES, 2019: 2020. 48. https://mycares.net/ sitepages/uploads/2020/2019_flipbook/index.html?page $=20$

13 Tjelmeland IBM, Masterson S, Herlitz J, et al. Description of emergency medical services, treatment of cardiac arrest patients and cardiac arrest registries in Europe. Scand J Trauma Resusc Emerg Med 2020;28:103.

14 Roessler M, Zuzan O. Ems systems in Germany. Resuscitation 2006;68:45-9.

15 Gräsner J-T, Meybohm P, Lefering R, et al. ROSC after cardiac arrest - the RACA score to predict outcome after out-of-hospital cardiac arrest. Eur Heart J 2011;32:1649-56.

16 Seewald S, Wnent J, Lefering R, et al. CaRdiac Arrest Survival Score (CRASS) - A tool to predict good neurological outcome after out-ofhospital cardiac arrest. Resuscitation 2020;146:66-73.

17 Fischer M, Wnent J, Gräsner JT. Jahresbericht des Deutschen Reanimationsregisters - Außerklinische reanimation 2019. Anästh Intensivmed 2020;61:89-93.

18 Tjelmeland IBM, Alm-Kruse K, Andersson L-J, et al. Cardiac arrest as a reportable condition: a cohort study of the first 6 years of the Norwegian out-of-hospital cardiac arrest registry. BMJ Open 2020;10:e038133.

19 von Elm E, Altman DG, Egger M, et al. Strengthening the reporting of observational studies in epidemiology (STROBE) statement: guidelines for reporting observational studies. BMJ 2007;335:806-8.

20 Jacobs I, Nadkarni V, Bahr J, et al. Cardiac arrest and cardiopulmonary resuscitation outcome reports: update and simplification of the Utstein templates for resuscitation registries: a statement for healthcare professionals from a task force of the International liaison Committee on resuscitation (American heart association, European resuscitation Council, Australian resuscitation Council, New Zealand resuscitation Council, heart and stroke Foundation of Canada, InterAmerican heart Foundation, resuscitation councils of southern Africa). Circulation 2004;110:3385-97

21 Strömsöe A, Svensson L, Axelsson Å B, et al. Validity of reported data in the Swedish cardiac arrest register in selected parts in Sweden. Resuscitation 2013;84:952-6.

22 Becker LB, Smith DW, Rhodes KV. Incidence of cardiac arrest: a neglected factor in evaluating survival rates. Ann Emerg Med 1993;22:86-91.

23 Statistical Office of the European Communities. Cardiovascular diseases statistics. Deaths from cardiovascular diseases. In: Eurostat, ed. European Commission's statistical office, 1990. Available: https://ec.europa.eu/eurostat/statistics-explained/ index.php?title=Cardiovascular_diseases_statistics\#Deaths_from_ cardiovascular diseases

24 Nolan JP, Soar J, Cariou A, et al. European resuscitation Council and European Society of intensive care medicine guidelines for post-resuscitation care 2015: section 5 of the European resuscitation Council guidelines for resuscitation 2015. Resuscitation 2015;95:202-22.

25 Holmén J, Herlitz J, Ricksten S-E, et al. Shortening ambulance response time increases survival in out-of-hospital cardiac arrest. $J$ Am Heart Assoc 2020;9:e017048.

26 Bürger A, Wnent J, Bohn A, et al. The effect of ambulance response time on survival following out-of-hospital cardiac arrest. Dtsch Arztebl Int 2018;115:541-8. 
27 Lim SL, Smith K, Dyson K, et al. Incidence and outcomes of outof-hospital cardiac arrest in Singapore and Victoria: a collaborative study. J Am Heart Assoc 2020;9:e015981.

28 Nasjonalt Servicemiljø for Medisinske Kvalitetsregistre. Resultat fra medisinske kvalitetsregistre (Results from medical quality registries) [Online]. SKDE; 2021 [cited 2021 12.01.2021]. Webpage where results from all approved national medical quality registries are published]. Available: https://www. kvalitetsregistre.no [Accessed 12 Jan 2021].
29 Rott N, Scholz KH, Busch HJ, et al. Cardiac arrest center certification for out-of-hospital cardiac arrest patients successfully established in Germany. Resuscitation 2020:156:1-3.

30 Perkins GD, Graesner J-T, Semeraro F, et al. European resuscitation Council guidelines 2021: Executive summary. Resuscitation 2021;161:1-60

31 Berwick DM, Nolan TW, Whittington J. The triple AIM: care, health, and cost. Health Aff 2008;27:759-69. 